\title{
Editorial
}

\section{Making soft drinks the dietary version of the cigarette}

You would think that these would be difficult times for sweetened beverages. Like any pursued criminal, they have aliases (a.k.a. soft drinks, a.k.a. soda, a.k.a. pop); researchers in nutritional epidemiology and public health nutrition have put the finger on them as contributors to the obesity epidemic; authorities on dietary recommendations are bearing down on them; law makers are scrambling to make them feel unwelcome. But, like any pursued criminal, they are fleeing to more welcoming shores, hoping to seek their fortune overseas.

And they are. In a blog posting from July of last year, Marion Nestle cited a Food Navigator news item reporting increases in sales and income for both PepsiCo and Coca-Cola despite 'challenging' or 'sluggish' sales in North America ${ }^{(1)}$. The pattern is uncomfortably similar to what has happened to tobacco, which experienced a rather definitive fall from grace in the 1990s but continues to thrive because of expanding markets in Asia. The soda industry would of course prefer not to acknowledge any similarity between cigarettes and sodas, but how can we not remark on it?

In this issue of Public Health Nutrition, several articles address the topic of sweetened beverages (or soft drinks, or sodas), from assessing the prevalence of their consumption to considering how to reduce it. An article by Ratnayake and Ekanayake ${ }^{(2)}$ demonstrates the extent to which soft drinks have infiltrated youths' diets. In Sri Lanka, in a clear demonstration of soft drinks seeking fortune in new lands, $81 \%$ of the 17 -year-olds in the sample drank soft drinks at least once weekly.

Not surprisingly, greater consumption in the Sri Lankan sample was associated with higher socio-economic status (SES), the reverse of what we observe in industrialized countries. In another study in this issue, conducted in Alberta, Canada, prevalence was higher among those residing in low-SES neighbourhoods than in high-SES neighbourhoods. But also noteworthy is how high the prevalence was, regardless of SES: in this sample, 40-55\% of 4-to 5-year olds - pre-school age! - drank soda at least once weekly ${ }^{(3)}$. Other work in this issue adds to the exponentially growing literature linking soft drinks to adverse health outcomes, and to adiposity in particular ${ }^{(4)}$.

Another uncomfortable parallel between soft drink and tobacco consumption is the focus on youths. The tobacco industry certainly targeted youths, and for a while had a highly successful run with their cartoonish Joe Camel advertisements in the USA. We all understand the importance of starting habits early, whether we are public health nutritionists or sellers of addictive substances.
So what to do? Taxes were successful in reducing consumption of cigarettes, particularly among youths, whose decisions are sensitive to price changes. While taxes on sodas have not been high enough to have much effect in the USA, Rivard et al. report in this issue that $36 \%$ of their American survey participants supported a tax as high as $20 \%$ on sugar-sweetened beverages and $39 \%$ said that such a tax would cause them to reduce their consumption ${ }^{(5)}$. Some data suggest that price changes alone will not effect long-term dietary change ${ }^{(6)}$. For places where a soda tax has already gone into effect - most recently the 'cola tax' in France - we would certainly welcome an evaluation of its effects in the pages of this journal.

Another lesson that can be learned from tobacco is the importance of changing social norms. For tobacco, taxes were just a start; what has evolved since then is the view that not smoking is the norm - an impressive public health success. Who in the 1960s would have imagined a time when smokers would be looked at askance? Analogously, can we today imagine a time in the future when soft drinks will be looked upon as ... well, the dietary version of a cigarette? It is time for us to change our norms. Soft drinks do not have to be the default drink at lunch, snack, dinner, or - for the diehard soda drinkers - breakfast. Won't a simple glass of water do?

A final lesson from the cigarette story is what happened to the tobacco industry itself. Political and legal attacks on the industry in the 1990s, including lawsuits by smokers and the leaking of internal industry documents, were instrumental in weakening its influence in the USA, and this was critical in bringing about more stringent regulation. It is hard to imagine what circumstances might bring about a similar shift in public opinion against the sweetened beverage industry. But here again we can draw some parallels. In an invited commentary also in this month's issue, Yanamadala et $a l .{ }^{(7)}$ report on their findings regarding Americans Against Food Taxes. The organization presents itself as a 'coalition of concerned citizens [...] opposed to the Government's proposed tax hike on food and beverages, including soda, juice drinks, and flavored milks, ${ }^{(8)}$. Yet this 'coalition' is less a grassroots organization of concerned citizens than it is an industry front group. The commentary goes on to discuss the importance of such misrepresentation, including the observation that this strategy resembles one used by RJ Reynolds in 1994. What is needed, really, is a way to keep the influence of the sweetened beverage industry in check. A shift in consumer perceptions of the industry, as a result of greater transparency, might play a role. 
In a way, the commentary by Yanamadala et al. ${ }^{(7)}$ brings this editorial to an ironic conclusion. We as public health professionals can draw useful lessons from the tobacco story. But the sweetened beverage industry is drawing some pretty useful lessons, too.

\section{Agneta Yngve} Editor-in-Chief

Irja Haapala Allison Hodge Geraldine McNeill Marilyn Tseng Deputy Editors

\section{References}

1. Nestle M (2011) Thanks to emerging markets, U.S. food companies grow profits. Food Politics. http://www.food politics.com/2011/07/emerging-markets-account-for-fast-foodand-soft-drink-sales-growth/ (accessed May 2012).
2. Ratnayake N \& Ekanayake L (2012) Soft drink consumption in Sri Lankan adolescents. Public Health Nutr 15, 1333-1337.

3. Pabayo RA, Spence JC, Cutumisu N et al. (2012) Sociodemographic, behavioural and environmental correlates of sweetened beverage consumption among pre-school children. Public Health Nutr 15, 1338-1346.

4. Rhee JJ, Mattei J \& Campos H (2012) Association between commercial and traditional sugar-sweetened beverages and measures of adiposity in Costa Rica. Public Health Nutr 15, $1347-1354$.

5. Rivard C, Smith D, McCann SE et al. (2012) Taxing sugarsweetened beverages: a survey of knowledge, attitudes and behaviours. Public Health Nutr 15, 1355-1361.

6. Dellava JE, Bulik CM \& Popkin BM (2010) Price changes alone are not adequate to produce long-term dietary change. J Nutr 140, 1887-1891.

7. Yanamadala S, Bragg MA, Roberto CA et al. (2012) Food industry front groups and conflicts of interest: the case of Americans Against Food Taxes (Invited Commentary). Public Health Nutr 15, 1331-1332.

8. Americans Against Food Taxes (date not available) About Us. http://www.nofoodtaxes.com/about/ (accessed May 2012). 